\title{
Characteristics and Early Outcomes of Forceps Deliveries in a Tertiary Clinical Center
}

\author{
Milica Cakic ${ }^{1}$ Ivana Likic Ladjevic ${ }^{1,2}$, Zoran Vilendecic ${ }^{1,2}$, Jelena Dotlic ${ }^{1,2}$ \\ ${ }^{1}$ Clinic for Obstetrics and Gynecology, Clinical Center of Serbia, Serbia, ${ }^{2}$ Faculty of Medicine, University of Belgrade, Serbia
}

Correspondence: drenadot@gmail.com; Tel./Fax.: + 381113615592

Received: July 14, 2020; Accepted: October 10, 2020

\begin{abstract}
Objective - The study aimed to investigate the characteristics of women and their children as well as the deliveries completed using forceps in one tertiary center. Material and Methods - The study included all women who had vaginal delivery during 2019. Women were classified according to use of the outlet forceps for delivery into the study and control group. We recorded maternal age and parity, duration of delivery, stimulation and epidural analgesia use, neonatal measures and Apgar score, maternal and neonatal complications after delivery. Results - Of the 3,570 vaginal births, forceps was applied 23 (0.64\%) times. Most women were aged $<35$ years and were primiparous. The indication for forceps use in all cases was the delay in the expulsion phase. Forceps deliveries lasted on average 6.20+/-2.15 hours. In both groups, birth canal injuries were frequently registered ( $\mathrm{P}=0.001$ ), while uterine atony was rare $(\mathrm{P}=0.001)$. Postpartum anemia was more frequent after forceps application, however, not significantly. A similar number of children with and without neonatal complications was registered $(\mathrm{P}=0.140)$. Children born using forceps had lower Apgar scores than those from the control group $(\mathrm{P}=0.046)$ and spent longer time in the intensive care unit $(\mathrm{P}=0.038)$. There were no other significant differences in any of the tested parameters of mothers and children between the study and the control group. Conclusion - Use of forceps is remarkably rare in our setting. Children born using forceps have less favorable early perinatal outcomes, but few serious long-term complications. If applied skillfully and according to indications, forceps is safe for both mothers and children.
\end{abstract}

Key Words: Forceps • Delivery • Patient Characteristics • Outcome.

\section{Introduction}

Operative termination of vaginal delivery can be performed using forceps or vacuum extractor, which shortens and facilitates fetal expulsion $(1,2)$. Application of forceps is an obstetric operation in which the fetal head is fixated and placed in a favorable position for birth. By traction and rotation of the forceps, obstetrician assists the delivery of the fetus. The decision to apply forceps is based on the bimanual examination of pregnant woman by obstetrician combined with diagnostic procedures such as the ultrasound biometry of the fetus and maternal pelvic measurements $(1,2)$.
The success or failure of the operative termination of vaginal delivery directly depends on the knowledge and skills of the obstetrician. Use of forceps has both advantages and disadvantages, however, if applied correctly during the second phase of the labor, it can eliminate the need for caesarean section $(3,4)$. Cesarean section is a more invasive procedure compared to forceps application and, therefore, complications after the cesarean section can be more complex. Given that the rate of the operative termination of vaginal delivery using forceps as well as the vacuum extractor has significantly been decreased over the recent years, future obstetricians are at risk of not sufficiently developing this skill or even losing it completely $(3,4)$. 
The forceps is applied in case when, even after several regular contractions, the fetus does not descend through the birth canal. Prerequisites for forceps use to terminate vaginal delivery are good knowledge of the very procedure, spontaneously ruptured or pierced amniotic sack, head presentation of the fetus, complete dilation and engaged head (5, 6). Forceps is contraindicated when the fetus is in a transverse position. The most common indications for forceps application relative to the condition of the mother are weak contractions, severe heart and lung diseases, large myopia and febrile conditions, while the main indication by the fetus is acute asphyxia. Out of all types of forceps, use of Negele's forceps is the most common in our settings. Concerning the place of application, the output forceps is typically applied nowadays. The procedure must be explained to the mother beforehand $(5,6)$.

Negele's obstetric forceps has two blades defined as left and right depending on the application side in the mother's pelvis. The blades are introduced separately and by locking are converted into one instrument. Each blade consists of a handle, a shank and the curved portion. The blades have outer pelvic and inner cephalic curves. The pelvic curve is shaped to follow the birth canal and help traction under the pubic bone. Moreover, the blades are fenestrated to receive the parietal protuberance for firmer grasp of the fetal head. The blades cross at a midpoint forming an articulation and the handles are connected to the blades. Negele's forceps has the knob at the end of the handle for locking the mechanism making it better for outlet nonrotational forceps delivery. Negele's forceps usually weights 625 grams and has the length of $379 \mathrm{~mm}$ (7).

The aim of the study was to examine the characteristics of mothers and their newborns as well as the deliveries that were completed using forceps in our tertiary center.

\section{Patients and Methods}

This case-control study included all pregnant women who gave birth vaginally at the Clinic for Obstetrics and Gynecology Clinical Center of Ser- bia during the year 2019. The study was approved by the Review Board of our Medical Faculty. Of all women, the study group included those whose labor was completed using the Negele's outlet forceps. Indications (diagnosis) for the application of forceps have been recorded for each delivery. The control group included the same number of pregnant women who were matched with the study group according to parity. The selection of women for the control group was based on the birth registry (from January 1, 2019, first woman of the corresponding in parity who delivered vaginally after the woman who delivered using forceps).

For all the examined women we register age, parity and comorbidities. Women were categorized as younger (under 35 years) and older (35 and more years of age at time of delivery). We also measured pelvic diameters for all women to confirm that vaginal delivery can be performed (external conjugate $\geq 18 \mathrm{~cm}$ ). The duration of delivery from the beginning of the active phase to the end of the expulsion was also recorded. We noted the gestational week (GW) of delivery, whether the delivery was induced, stimulated by Oxytocin or spontaneous, as well as whether the mother received epidural analgesia during delivery. Of the characteristics of newborns i.e. neonates (any baby live-born at $\geq 28 \mathrm{GW}$, weighing $\geq 1000$ grams at birth, from birth to 28 days of age) we registered gender, length, head circumference, birth weight, as well as the Apgar score in the first minute. The weight of the newborn was categorized as reduced (up to $3000 \mathrm{gr}$ ), adequate (from 3000 to 4000 gr) and increased (over 4000 gr). Determining the Apgar score is a method of rapid assessment of the newborn's vitality based on the ratings of their heart rate, respiration, skin color, muscle tone and response to stimulation with a 0,1 or 2 . The score of the ratings of 8 or higher indicates a good health condition of the newborn. In this study, only the 1st minute Apgar score was examined as a major indicator of the immediate obstetric outcome.

After delivery, it was determined whether the placenta was intact, defective or adherent. Women underwent a gynecological exam for any lacerations 
or ruptures of the soft tissues of the birth canal (cervix, vagina, perineum). Women were closely monitored for any symptoms and signs of uterine atony. Laboratory tests and blood count were performed on the first postpartum day as well as prior to discharge from the Clinic. In case anemia was diagnosed, they were appropriately treated (Fe substituent or blood transfusions). As for the newborns, we noted all early postpartum complications (injuries, torticollis, myotonia, respiratory distress, jaundice) as well as the time (days) spent in the neonatal intensive care unit (NICU). If no complications occurred, the mothers and their children were discharged on the third day after delivery.

\section{Statistical Analysis}

The obtained data were analyzed by methods of descriptive (arithmetic mean, standard deviation, number and percentage) and analytical statistics (t-test and $\chi 2$ test) using the computer statistical program SPSS 20. For comparison of the characteristics of mothers and children from the study and control group we applied the ANOVA and Kruskall-Wallis $\chi^{2}$ test. To investigate factors that impact neonatal outcomes after forceps delivery we used multiple linear and binary regression analyses. In linear regression the outcome was Apgar score upon birth while in binary regression having com- plications was assessed as the dependent variable. Investigated parameters were grouped as fetal and maternal and in that way used as independent variables in both analyses. The level of significance was 0.05 .

\section{Results}

At the Clinic for Obstetrics and Gynecology Clinical Center of Serbia in 2019, a total of 3,570 pregnant women gave birth vaginally. Outlet forceps was applied in only $23(0.64 \%)$ deliveries. In all the registered cases, the indication for forceps application was a delay in the expulsion phase. We presented the characteristics of the examined mothers and children in Table 1. The frequency of the tested parameters is shown in Table 2.

Only two $(4.35 \%)$ pregnant women who were delivered using forceps were secundiparous, while all other examined women were primiparous $(\mathrm{P}=0.001)$. The age of women from the study group ranged from 19 to 41 years and age in the control group ranged from 18 to 40 years. In both the study and the control group the majority of mothers were younger than 35 years. Birth canal injuries were frequently registered $(39.1 \%$ of all women; $\mathrm{P}=0.002$ ). The majority of women who were delivered using forceps had multiple injuries of the birth canal (perineum, vagina and uterine cervix), while

\section{Table 1. Characteristics of Mothers and Children Born with and without the Use of Forceps}

\begin{tabular}{lllllll}
\hline \multirow{2}{*}{ Parameters } & \multicolumn{2}{l}{ Forceps group } & \multicolumn{2}{l}{ Control group } & \multicolumn{2}{l}{ Between groups } \\
\cline { 2 - 8 } & Mean & SD & Mean & SD & F & P \\
\hline Maternal age & 31.01 & 6.38 & 29.34 & 6.12 & 0.802 & 0.376 \\
\hline External conjugate diameter & 19.76 & 1.02 & 19.19 & 0.96 & 3.733 & 0.060 \\
\hline Hemoglobin levels after birth & 102.47 & 24.22 & 106.13 & 14.58 & 0.385 & 0.538 \\
\hline Delivery duration & 6.45 & 2.26 & 6.18 & 1.94 & 0.190 & 0.665 \\
\hline Neonatal length at birth & 50.26 & 5.16 & 51.13 & 1.63 & 0.593 & 0.445 \\
\hline Head circumference at birth & 35.17 & 1.66 & 33.27 & 0.93 & 0.471 & 0.263 \\
\hline Neonatal weight at birth & 3530.43 & 463.31 & 3610.86 & 381.78 & 0.413 & 0.524 \\
\hline Apgar score 1st minute & 7.73 & 1.73 & 9.01 & 0.01 & 12.109 & 0.001 \\
\hline Gestational week at delivery & 38.86 & 1.28 & 38.52 & 1.12 & 0.951 & 0.335 \\
\hline Intensive care days & 7.17 & 8.69 & 3.78 & 2.04 & 9.385 & 0.038 \\
\hline
\end{tabular}

"Standard deviation. 
Table 2. Frequency of Tested Parameters of Mothers and Children Born with and without Forceps

\begin{tabular}{|c|c|c|c|c|c|}
\hline \multirow{2}{*}{ Parameters } & & \multirow{2}{*}{$\begin{array}{l}\text { Forceps group } \\
\mathrm{N}(\%) \\
\end{array}$} & \multirow{2}{*}{$\begin{array}{l}\text { Control group } \\
\mathrm{N}(\%) \\
\end{array}$} & \multicolumn{2}{|c|}{ Between groups } \\
\hline & & & & $\mathrm{KW} \chi^{2}$ & $\mathrm{P}$ \\
\hline \multirow{3}{*}{ Maternal age categories } & Younger* & $15(65.2)$ & $18(78.3)$ & \multirow{3}{*}{0.944} & \multirow{3}{*}{0.331} \\
\hline & Older $^{\dagger}$ & $8(34.8)$ & $5(21.7)$ & & \\
\hline & $\mathrm{P}^{\ddagger}$ & 0.144 & 0.007 & & \\
\hline \multirow{3}{*}{ Previous parity } & 1 & $21(91.3)$ & $23(100)$ & \multirow{3}{*}{2.045} & \multirow{3}{*}{0.153} \\
\hline & 2 & $2(8.7)$ & $0(0)$ & & \\
\hline & $\mathrm{P}^{\ddagger}$ & 0.001 & 0.001 & & \\
\hline \multirow{3}{*}{ Comorbidities } & No & $15(65.2)$ & $14(60.9)$ & \multirow{3}{*}{0.091} & \multirow{3}{*}{0.763} \\
\hline & Yes & $8(34.8)$ & $9(39.1)$ & & \\
\hline & $\mathrm{P}^{\ddagger}$ & 0.144 & 0.297 & & \\
\hline \multirow{3}{*}{ Epidural analgesia } & No & $16(69.6)$ & 2087.0 & \multirow{3}{*}{2.000} & \multirow{3}{*}{0.157} \\
\hline & Yes & $7(30.4)$ & 313.0 & & \\
\hline & $\mathrm{P}^{\ddagger}$ & 0.061 & 0.001 & & \\
\hline \multirow{4}{*}{ Placenta at birth } & Whole & $3(13.0)$ & $13(56.5)$ & \multirow{4}{*}{7.332} & \multirow{4}{*}{0.007} \\
\hline & Defect & $17(73.9)$ & $8(34.8)$ & & \\
\hline & Adherent & $3(13.0)$ & $2(8.7)$ & & \\
\hline & $\mathrm{P}^{\ddagger}$ & 0.001 & 0.019 & & \\
\hline \multirow{4}{*}{ Birth canal injuries } & No & $5(21.7)$ & $4(17.4)$ & \multirow{4}{*}{1.930} & \multirow{4}{*}{0.165} \\
\hline & Perineum & $4(17.4)$ & $12(52.2)$ & & \\
\hline & Multiple & $14(60.9)$ & $7(30.4)$ & & \\
\hline & $\mathrm{P}^{\ddagger}$ & 0.019 & 0.119 & & \\
\hline \multirow{3}{*}{ Uterine atony } & No & $17(73.9)$ & $19(82.6)$ & \multirow{3}{*}{0.500} & \\
\hline & Yes & $6(26.1)$ & $4(17.4)$ & & 0.480 \\
\hline & $\mathrm{P}^{\ddagger}$ & 0.022 & 0.002 & & \\
\hline & No & $13(56.5)$ & $17(73.9)$ & & \\
\hline Postpartum anemia & Yes & $10(43.5)$ & $6(26.1)$ & 1.500 & 0.221 \\
\hline & $\mathrm{P}^{\ddagger}$ & 0.532 & 0.022 & & \\
\hline & Male & $14(60.9)$ & $12(52.2)$ & & \\
\hline Neonatal gender & Female & $9(39.1)$ & $11(47.8)$ & 0.346 & 0.556 \\
\hline & $\mathrm{P}^{\ddagger}$ & 0.297 & 0.835 & & \\
\hline & $<3000$ grams & $5(21.7)$ & $3(13.0)$ & & \\
\hline 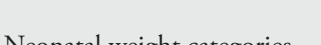 & 3000 to 4000 grams & $15(65.2)$ & 17 73.9) & 0204 & 0508 \\
\hline Neonatal weignt categorles & $\geq 4000$ grams & $3(13.0)$ & $3(13.0)$ & 0.294 & 0.588 \\
\hline & $\mathrm{P}^{\ddagger}$ & 0.005 & 0.001 & & \\
\hline & Torticollis & $7(30.4)$ & $2(8.7)$ & & \\
\hline & Bone fractures & $0(0)$ & $2(8.7)$ & & \\
\hline & Myotonia & $0(0)$ & $1(4.3)$ & & \\
\hline Neonatal complications type & Hematomas & $3(13.0)$ & $2(8.7)$ & 3.284 & 0.070 \\
\hline & Respiratory distress & $2(8.7)$ & $0(0)$ & & \\
\hline & Jaundice & $2(8.7)$ & $7(30.4)$ & & \\
\hline & $\mathrm{P}^{\ddagger}$ & 0.062 & 0.014 & & \\
\hline & No & $9(39.1)$ & $9(39.1)$ & & \\
\hline Complications presence & Yes & $14(60.9)$ & $14(60.9)$ & 0.001 & 1.000 \\
\hline & $\mathrm{P}^{\ddagger}$ & 0.297 & 0.297 & & \\
\hline
\end{tabular}

${ }^{*}<35$ years; ${ }^{\dagger} \geq 35$ years; ${ }^{*}$ Based on Hi square test. 


\begin{tabular}{|c|c|c|c|c|c|c|c|c|}
\hline \multirow{2}{*}{ Model } & & \multicolumn{2}{|c|}{$\begin{array}{l}\text { Unstandardized } \\
\text { coefficients }\end{array}$} & \multirow{2}{*}{$\begin{array}{l}\text { Standard } \\
\text { Beta }\end{array}$} & \multirow{2}{*}{$\mathrm{t}$} & \multirow{2}{*}{$\mathrm{P}$} & \multicolumn{2}{|c|}{$\begin{array}{l}95 \% \text { Confidence } \\
\text { interval for B }\end{array}$} \\
\hline & & B & $S E^{\|}$ & & & & $\begin{array}{l}\text { Lower } \\
\text { Bound }\end{array}$ & $\begin{array}{l}\text { Upper } \\
\text { Bound }\end{array}$ \\
\hline \multirow{2}{*}{ Unadjusted } & Constant & 6.478 & 0.573 & - & 11.307 & 0.001 & 5.324 & 7.633 \\
\hline & Group F/C & 1.261 & 0.362 & 0.465 & 3.480 & 0.001 & 0.531 & 1.991 \\
\hline \multirow{6}{*}{$\begin{array}{l}\text { Adjusted } \\
\text { for fetal } \\
\text { characteristics }\end{array}$} & Constant & 6.269 & 7.899 & - & 0.794 & 0.032 & -9.696 & 22.233 \\
\hline & Group F/C & 1.228 & 0.390 & 0.453 & 3.150 & 0.003 & 0.440 & 2.016 \\
\hline & Length & 0.030 & 0.086 & 0.082 & 0.344 & 0.733 & -0.145 & 0.204 \\
\hline & Head & -0.153 & 0.251 & -0.149 & -0.610 & 0.546 & -0.660 & 0.354 \\
\hline & Weight & 0.000 & 0.001 & 0.120 & 0.685 & 0.498 & -0.001 & 0.002 \\
\hline & Gest $^{\dagger}$ week & 0.071 & 0.176 & 0.062 & 0.403 & 0.689 & -0.285 & 0.426 \\
\hline \multirow{7}{*}{$\begin{array}{l}\text { Adjusted for } \\
\text { maternal factors }\end{array}$} & Constant & 8.346 & 4.747 & - & 1.758 & 0.007 & -1.257 & 17.948 \\
\hline & Group F/C & 1.160 & 0.409 & 0.427 & 2.835 & 0.007 & 0.332 & 1.987 \\
\hline & Age & 0.013 & 0.036 & 0.061 & 0.371 & 0.713 & -0.060 & 0.087 \\
\hline & Parity & -0.509 & 0.984 & -0.076 & -0.517 & 0.608 & -2.499 & 1.481 \\
\hline & Comorbidity & 0.554 & 0.468 & 0.197 & 1.183 & 0.244 & -0.393 & 1.502 \\
\hline & Externa $^{\ddagger}$ & -0.082 & 0.209 & -0.061 & -0.392 & 0.697 & -0.505 & 0.341 \\
\hline & Delivery $^{\S}$ & -0.031 & 0.092 & -0.048 & -0.341 & 0.735 & -0.218 & 0.155 \\
\hline
\end{tabular}

"Group delivered using forceps versus control group; ${ }^{\dagger}$ Gestation; ${ }^{\ddagger}$ External conjugate length; ${ }^{\S}$ Duration; "Standard error.

women from the control group mostly had perineum lacerations and ruptures. Uterine atony was rare in both groups of women. In the control group, most women did not have postpartum anemia, while there were no significant differences regarding the frequency of postpartum anemia among women who were delivered using forceps.

There were no significant differences regarding neonatal gender both in the study and in the control group. In both groups, the majority of children had adequate weight, while a similar number of children had reduced and increased birth weight. The mean $+/$ - SD Apgar score in the study group was $7.73+/-1.73$ and in the control group the average Apgar score was $9.01+/-0.01$. All children from both study and control group were delivered in term (minimum 37 maximum 41). We registered a similar number of children with and without neonatal complications in both groups. Concerning the complications in children who were delivered using forceps, they mostly had torticollis and those delivered spontaneously had jaundice in the first days after birth.
All the examined deliveries from both groups were stimulated with Oxytocin. There were no induced labors in our sample. Deliveries of women from the study group lasted from 3 to 12 hours. Similarly, births of women from the control group lasted from 4 to 12 hours. Epidural analgesia was rarely administered to our patients.

When we compared the study and the control group, it was seen that there were no significant differences between the groups in almost any of the examined characteristics of mothers and their children. On the other hand, children born using forceps had a significantly lower Apgar score at birth and spent almost twice as longer time in the NICU than children born without forceps. Placentas from deliveries that ended using forceps were more often defective or adherent, so a revision of the uterine cavity is advised.

Finally, unadjusted linear regression analysis showed that forceps use was associated with lower Apgar score of the fetus upon birth $(\mathrm{R}=0.465$; $\left.\operatorname{adj} R^{2}=0.698 ; \mathrm{F}=12.109 ; \mathrm{P}=0.001\right)$. Moreover it was confirmed that forceps application was sig- 
nificantly associated with lower Apgar score both when the models were adjusted for fetal $(\mathrm{R}=0.486$; $\left.\operatorname{adj} R^{2}=0.641 ; \quad F=2.480 ; \quad P=0.048\right)$ and maternal parameters $\quad\left(\mathrm{R}=0.517 ; \quad \operatorname{adj} \mathrm{R}^{2}=0.655 ; \quad \mathrm{F}=2.375\right.$; $\mathrm{P}=0.047$ ). However, there was no association of forceps delivery with having early neonatal postpartum complication $(\mathrm{P}=0.257)$. Furthermore, other investigated parameters were not associated with the neonatal outcome (Table 3).

\section{Discussion}

For the past several decades worldwide, the overall instrumental delivery rates seem to be similar and they consistently remain around 18 to $22 \%$ of all deliveries (8). Conversely, the use of forceps has declined significantly by year 2000 reaching the lowest level of only $4 \%$ (1 in 25). This incidence of forceps deliveries is also registered nowadays while the vacuum extraction and caesarean sections have become more popular (9). The results of our study showed that in 2019, in our tertiary reference center, forceps was applied in less than $1 \%$ of births, and in almost all of the cases for primiparous women. A similar study conducted in India found that primiparous women represented $65.8 \%$ of cases in which the forceps was applied during delivery (10).

If applied correctly, use of forceps is generally safe and can be used to assist the delivery at any length of gestation. Some studies support the use of output forceps as a safer alternative to the cesarean section as it may reduce the risk of hypoxic ischemic neonatal encephalopathy $(2,4)$. On the other hand, forceps application during delivery can have short and long-term traumatic consequences for both newborns (subdural or cerebral hemorrhage, convulsions and the need for mechanical ventilation all potentially causing neurological and developmental disorders) and mothers (bleeding, perineum tissue injuries) $(11,12)$.

Most studies indicate that perineum trauma such as second and third degree lacerations more likely occur when using forceps than in natural deliveries $(8,11)$. The rate of periurethral injuries and perineum hematomas are also quite frequent in operative vaginal deliveries. Therefore, some literature data suggest that after forceps application women are at greater risk of urinary and fecal incontinence, but it seems that no significant complications remain in long-term ( $\geq 5$ years) $(13,14)$. Moreover, according to some other investigations, less than $10 \%$ of women had perineum tears and only $2 \%$ had hematomas with no significant damages to the birth canal in case of adequate application of forceps $(8,9)$. Still, there is a general consensus that appropriate training is necessary before carrying out a forceps delivery $(8,9)$.

Studies have shown that for a good delivery outcome, the most important thing is to maintain the procedure of forceps application the as short as possible. In contrast, the number of withdrawals as well as the total duration of delivery was not confirmed to significantly affect the perinatal outcome $(15,16)$. In our study, there were no significant differences in total duration of delivery between the study and control group of patients. This may be the reason for having few maternal and neonatal complications after application of the forceps. Because of this, developing good technical skills when performing emergency operative deliveries as well as following the guidance about indications for forceps application are being emphasized $(4,5)$.

Use of medications for labor induction and augmentation was found to be a risk factor for forceps delivery $(17,18)$. However, deliveries that we examined were all stimulated (in the study and control group as well), so we were unable to test the impact of stimulation on the need for forceps use.

Moreover, according to the protocols all placentas are thoroughly examined after delivery. The revision of the uterine cavity is indicated in case of defective placenta to prevent postpartum bleeding. We noted that placentas of women from the study group were more often defective or adherent, so a revision of the uterine cavity should always be considered after using forceps.

When we analyzed the reasons for forceps application in our sample, the delay in the second phase of delivery (expulsion phase) was singled out as the 
indication in all the examined cases. Our findings are in accordance with recent data from literature, where the leading indications for forceps application were suggested to be fetal distress (identified by continuous cardiotocographic monitoring) (46.3\%-78.1\%), prolonged second stage of delivery (about $20 \%$ of cases) as well as the weak labor forces i.e. inadequate contractions (about 30\% of cases) $(10,15,19)$. Previous research suggested that avoiding induction of labor may reduce the risk for forceps application, although these findings have not been confirmed by recent studies (16). There were no cases of induced deliveries in our study, but all patients received Oxytocin stimulation, regardless of the delivery method.

Another investigation showed that most newborns delivered using forceps had adequate weight at birth (19). These findings correspond to the results of our study where the adequate birth weight was registered for $65.2 \%$ of newborns. Data from literature indicate that fetal head circumference and angle of head progression through the birth canal are the most important predictors of complicated operative vaginal delivery (20). One of the models to predict the possibility of spontaneous vaginal birth is based on the six parameters that can be defined in the first stage of labor (head distance to perineum, presence of caput succedaneum, posterior occipital position, gestational week at birth, age and body mass index of the mother) (20). In cases when neonatal weight is lower than expected for gestational age, a combined model incorporating antenatal and intrapartum risk factors such as gestational age at birth, cerebroplacental ratio in MoMs, maternal parity, induction of labor, stimulation of labor with Oxytocin and use of epidural analgesia may be used to predict the delivery outcome (21). In our study, there were no significant differences in the examined characteristics of both mothers and their newborns, which could indicate complications of delivery and the need to complete the vaginal delivery using forceps. Moreover, the performed regression analysis showed that forceps application could impact immediate obstetric outcome, but is not associated with early neonatal complications.
Other investigated parameters were not reliable predictors of adverse neonatal outcomes.

Regarding perinatal outcomes, neonatal complication rates and morbidity significantly vary among previously published reports. The most common early fetal complications are various injuries (cephalhematomas, clavicle fracture, brachial plexus injury, etc.) and respiratory distress $(12,22)$. Some studies found that NICU admissions were significantly more common and longer after forceps application than after natural deliveries. According to literature, average time spent in NICU for children delivered using forceps is around one week $(11,23)$. In our study, hematomas were registered in $13 \%$ and respiratory distress syndrome in $8.7 \%$ of children born using forceps. Children born using forceps also stayed for one week in NICU, on average, and this was significantly longer than the time spent in NICU after regular vaginal deliveries.

The influence of instrumental deliveries on Apgar score remains controversial. While some authors found that $1 \mathrm{~min}$ Apgar score $\leq 4$ was more common after forceps delivery, other studies did not confirm this finding. Some studies have reported that as many as $10 \%$ of newborns delivered using forceps have an Apgar score of less than four in the first minute $(10,22)$. However, it should be noted that in these studies the indication for forceps application was fetal distress, which itself could significantly reduce the Apgar score of newborns (23). This is supported by the conclusions of a study conducted in Spain where the Apgar score of newborns delivered by forceps averaged at 8.7, which is slightly higher than the mean Apgar score of 7.95 obtained in our study (20).

Finally, it should be mentioned that the significant study limitation was the small sample size. However, forceps is rarely applied nowadays even in large delivery wards. Consequently, further multicentre studies on a larger sample are still needed to better explain the complications and consequences of forceps use. Moreover, another potential limitation is the fact that the study was designed as casecontrol which limited possibility to draw causal inference from the obtained models. Therefore, 
to confirm the contributory effects of forceps on early neonatal outcome these future studies should be prospective starting from early pregnancy and including more potential pregnancy complications rather than retrospective like the one we performed.

\section{Conclusion}

Use of forceps is quite rare in our clinical setting. On the other hand, when forceps was applied, it was more often during deliveries of younger women, especially those who are primiparous. The indication for forceps application was mostly a delay in the expulsion phase, which was not conditioned by the size of the fetus, duration of labor, use of Oxytocin stimulation or epidural analgesia. Children born using forceps had few major complications, but did have a lower Apgar score at birth and spent longer time in NICU than those born without forceps. Still, if applied skillfully and within indications, use of forceps can be safe for both mother and child.

Conflict of Interest: The authors declare that they have no conflict of interest.

Authors' Contributions: Conception and design: $\mathrm{MC}$ and ILL; Acquisition, analysis and interpretation of data: MC, ZV and JD; Drafting the article: MC, JD, ZV and ILL; Revising it critically for important intellectual content: ILL and JD; Approved final version of the manuscript: MC, JD, ZV and ILL.

\section{References}

1. Qiufeng L, Jie X, Xiahong W, Lixin Y. Changes and analysis of transvaginal forceps delivery rate in primary hospitals in the past 10 years. Gin Pol. 2019;90(12):711-6.

2. Merriam AA, Ananth CV, Wright JD, Siddiq Z, D'alton M, Friedman AM. Trends in operative vaginal delivery, 2005-2013: a population-based study. BJOG. 2017;124(9):1365-72.

3. Rather H, Muglu J, Veluthar L, Sivanesan K. The art of performing a safe forceps delivery: a skill to revitalise. Eur J Obstet Gynecol Reprod Biol. 2016;199:49-54.

4. O'Grady JP, Pope CS, Hofffman DE. Forceps delivery. Best Pract Res Clin Obstet Gynaecol.2002;16(1):1-16.

5. Cargill YM, MacKinnon CJ. No 148 Guidelines for operative vaginal birth. J Obstet Gynaecol Can. 2018;40(2):e74e80.
6. Vayssiere C, Beucher G, Dupuis O, Feraud O, SimonToulza C, Sentilhes L, et al. Instrumental delivery: clinical practice guidelines from the French College of Gynaecologists and Obstetricians. Eur J Obstet Gynecol Reprod Biol. 2011;159(1):43-8.

7. Matsumoto N, Takenaka T, Ikeda N, Yazaki S, Sato Y. Naegele Forceps Delivery and Association between Morbidity and the Number of Forceps Traction Applications: A Retrospective Study. J Pregnancy. 2015. doi: $10.1155 / 2015 / 483195$

8. Talukdar S, Purandare N, Coulter-Smith S, Geary M. Is it Time to Rejuvenate the Forceps? J Obstet Gynaecol India. 2013;63(4):218-22.

9. Demissie K, Rhoads GG, Smulian JC, Balasubramanian BA, Gandhi K, Joseph KS, et al. Operative vaginal delivery and neonatal and infant adverse outcomes: population based retrospective analysis. BMJ. 2004;329(7456):24-9.

10. John LB, Nischintha S, Ghose S. Outcome of forceps delivery in a teaching hospital: A 2 year experience. J Nat Sci Biol Med. 2014;5(1):155-7.

11. Murphy DJ, Liebling RE, Verity L, Swingler R, Patel R. Early maternal and neonatal morbidity associated with operative delivery in second stage of labour: a cohort study. Lancet. 2001;358(9289):1203-7.

12. Prapas N, Kalogiannidis I, Masoura S, Diamanti E, Make$\operatorname{dos}$ A, Drossou D, et al. Operative vaginal delivery in singleton term pregnancies: short-term maternal and neonatal outcomes. Hippokratia. 2009;13(1):41-5.

13. De Leeuw JW, Struijk PC, Vierhout ME, Wallenburg HC. Risk factors for third degree perineal ruptures during delivery. BJOG. 2001;108(4):383-7.

14. Dupuis O, Madelenat P, Rudigoz RC. Fecal and urinary incontinence after delivery: risk factors and prevention. Gynecol Obstet Fertil. 2004;32(6):540-8.

15. Black M, Murphy DJ. Forceps delivery for non-rotational and rotational operative vaginal delivery. Best Pract Res Clin Obstet Gynaecol. 2019;56:55-68.

16. Miller ES, Lai Y, Bailit J, Reddy UM, Wapner RJ, Varner MW, et al. Duration of Operative Vaginal Delivery and Adverse Obstetric Outcomes. Am J Perinatol. 2020;37(5):503-10.

17. Mazouni C, Porcu G, Bretelle F, Loundou A, Heckenroth H, Gamerre M. Risk factors for forceps delivery in nulliparous patients. Acta Obstet Gynecol Scand. 2006;85(3):298-301.

18. Xie RH, Cao H, Hong B, Sprague AE, Walker M, Wu Wen S. Occurrence and predictors of vacuum and forceps used sequentially for vaginal birth. J Obstet Gynaecol Can. 2013;35(4):317-322. 
19. Jabeen N, Baloch R, Malhi P, Zahiruddin S, Mawani $\mathrm{K}$. Foeto-maternal outcome in instrumental vaginal delivery attending a secondary hospital in Hyderabad (Aga Khan Maternal and Child Care Centre). JPMA. 2017;67(12):1833-6.

20. Sainz JA, Garcia-Mejido JA, Aquise A, Borrero C, Bonomi MJ, Fernandez-Palacin A. A simple model to predict the complicated operative vaginal deliveries using vacuum or forceps. Am J Obstet Gynecol. 2019;220(2):193e1-e12.

21. Kalafat E, Morales-Rosello J, Thilaganathan B, Tahera F, Khalil A. Risk of operative delivery for intrapartum fetal compromise in small-for-gestational-age fetuses at term: an internally validated prediction model. Am J Obstet Gynecol. 2018;218(1):134e1-e8.

22. Muraca GM, Skoll A, Lisonkova S, Sabr Y, Brant R, Cundiff GW, et al. Perinatal and maternal morbidity and mortality among term singletons following midcavity operative vaginal delivery versus caesarean delivery. BJOG. 2018;125(6):693-702.

23. Johnson JH, Figueroe R, Garry D, Elimian A, Maulic D. Immediate maternal and neonatal effects of forceps and vacuum-assisted deliveries. Obstet Gynecol. 2004;103(3):513-8. 